\title{
Barriers and enablers in integrating cognitive apprenticeship methods in a Web-based educational technology course for K-12 (primary and secondary) teacher education
}

\author{
Michele D. Dickey* \\ Miami University, USA
}

\begin{abstract}
The purpose of this study is to investigate the integration of a cognitive apprenticeship model into an educational technology Web-based course for pre-service primary through secondary teacher education. Specifically, this study presents an overview of methods, tools and media used to foster the integration of a cognitive apprenticeship model, and presents the types of barriers and enablers encountered when attempting to participate in a computer-mediated cognitive apprenticeship. The methodological framework for this investigation is a qualitative case study of an educational technology course for pre-service primary through secondary teacher education. The findings of this study reveal that various tools, methods and media were used to varying degrees of success to foster cognitive apprenticeship methods in a Web-based learning environment. The goal of this study was to better understand the pragmatics, suitability, affordances and constraints of integrating cognitive apprenticeship methods in a Web-based distance education course for teacher education.
\end{abstract}

\section{Introduction}

With the widespread adoption of the International Society for Technology in Education standards in the United States for integrating technology into primary and secondary education and an increasingly greater emphasis being placed on educational technology in primary through secondary education worldwide, it is important that educational technology programs for pre-service primary through secondary teacher education students find innovative methods and models for the effective use of technology in teaching and learning. However, this poses a challenge

\footnotetext{
*Educational Psychology, McGuffey Hall 100D, Oxford, OH 45056, USA. Email: dickeymd@ muohio.edu
} 
for pre-service teacher education programs attempting to provide distance education. Traditionally, pre-service teacher education students become enculturated into an authentic practice by taking university classes and by participating in field experiences in primary and secondary classrooms. Typically these experiences culminate in a student-teaching experience. However, this process changes with the use of Web-based courses or programs, which may in many ways seem antithetical to this enculturation process. All too often, Web-based instruction is reduced to uninspiring content presented in a linear text-based format (Daviault \& Coelho, 2003). Transposed lectures and text-based content do little to model or enculturate preservice teachers into the practice of integrating technology for their future teaching practice. Yet, because cognitive apprenticeship methods foster the emergence of practical skills within an authentic setting, finding methods of integrating cognitive apprenticeship methods in Web-based environments may provide an effective means to help enculturate pre-service primary through secondary teacher education students into the practice of integrating technology into their future teaching practices.

The purpose of this study is to investigate the integration of a cognitive apprenticeship model into an educational technology Web-based course for pre-service primary and secondary teacher education students in an American university. Specifically, this study presents an overview of methods, tools and media used to foster the integration of a cognitive apprenticeship model, and presents the types of barriers and enablers encountered when attempting to participate in a computer-mediated cognitive apprenticeship. The goal of this study is to better understand the pragmatics, suitability, affordances and constraints of integrating cognitive apprenticeship methods in a Web-based distance education course for teacher education.

\section{Theoretical framework}

Pre-service K-12 (primary and secondary) teacher education students are in the process of being educated within a field of practice. It is important to reinforce that notion, yet difficult to achieve in Web-based courses. According to Brown et al. (1996), prior to the emergence of formal schooling, the apprenticeship model was the most common means of educating learners in fields of practice. Cognitive apprenticeship methods consist of several stages (Collins et al., 1989). First the teacher identifies and models the expert-level practices or strategies for learners. Next, the teacher designs 'scaffolds' that will support learners in their attempt to apply expert practices or strategies. The term scaffold as applied to teaching is used to describe the temporary support framework provided to support learners in the process of extending competencies (Bransford et al., 2000). Scaffolding may take many forms and serve various functions. Hannafin et al. (1999) identified four types of scaffolding to include: conceptual, meta-cognitive, procedural and strategic. Conceptual scaffolding provides learners with hints and recommendations. Meta-cognitive scaffolding helps students plan, organize, reflect and regulate during an activity (Brown, 1998). Procedural scaffolding includes support that helps students to perform a task, action 
or process. Strategic scaffolding provides supports that help learners in applying knowledge, principles and experiences to various and new situations. Scaffolding can be provided in many forms and may include various resources and media. Although scaffolding is an important element, coaching is also an important part of cognitive apprentice methods. Whereas scaffolding may be related to individual areas, the role of coaching is much broader with the purpose of overseeing the student learning process (Collins et al., 1991). The teacher coaches the students in the process of adopting and using the expert practices or strategies by offering guidance during the entire process and by critiquing performance and offering feedback throughout.

While students are adopting and learning new practices, they are strongly encouraged to articulate their reasoning in using various strategies and practices. They are encouraged to reflect on their own experiences as well as those of their classmates. During this process the teacher gradually reduces or fades the support (coaching) as learners move towards independently applying what they have learned to new challenges. Because cognitive apprenticeship methods foster the emergence of practical skills within an authentic setting, it may provide an effective means to enculturate preservice primary and secondary teacher education students into the practice of integrating technology into their future teaching practices. Cognitive apprenticeship methods may be particularly well-suited for a Web-based environment for educational technology because students must use educational technology to learn about educational technology.

\section{Literature review}

There have been several notable studies on the integration of technology and cognitive apprenticeship methods (Järvelä, 1995; Liu, 1998; Liu \& Pedersen, 1998; Hendricks, 2001; Liu \& Hsaio, 2002), although relatively few explicitly investigate the use of cognitive apprenticeship methods in a Web-based environment. Research has been conducted about the integration of cognitive apprenticeship methods in the design of Internet-delivered online video case studies to support early literacy instruction for pre-service teachers (Schrader et al., 2003). Although the distribution of the video case studies was online, the course itself was taught in a traditional classroom format. The findings of the study by Schrader et al. indicate that video case studies of best practices helped initiate conversation and allowed learners multiple perspectives. In contrast, Saarenkunnas et al. (2000) investigated the integration of cognitive apprenticeship methods in the form of case-based conferencing for a Finnish and American collaborative course for pre-service teachers. The underlying technology that supported the collaborative course relied upon the use of both Web-based asynchronous conferencing tools and video conferencing. Although the focus of the study by Saarenkunnas et al. (2000) is primarily on the Web-based discussions, the findings indicate that the integration of cognitive apprenticeship methods did enhance learning. Both of these findings indicate value and potential for integrating cognitive apprenticeship methods in Web-based instruction. It is also worthy to note that in both the initiatives by Schrader et al. (2003) and Saarenkunnas et al. (2000), designers 
and researchers relied on the use of existing technologies such as digital video, video conferencing and discussion forums rather than developing new technologies for the integration of cognitive apprenticeship methods for teaching and learning.

Although there have been numerable studies of the integration of technology and cognitive apprenticeship methods (Järvelä, 1995; Liu, 1998; Liu \& Pedersen, 1998; Hendricks, 2001; Liu \& Hsaio, 2002), few of these studies have focused on the use of cognitive apprenticeship methods in a Web-based environment. As an increasing number of programs worldwide offer courses online, it is important to explore how innovative methods such as the cognitive apprenticeship model can be integrated into online learning environments to enhance teaching and learning. The purpose of this study is to investigate the integration of a cognitive apprenticeship model into an educational technology Web-based course for pre-service primary and secondary teacher education students in an American university by examining the methods, tools and media used to foster a cognitive apprenticeship model and to examine the types of barriers and enablers encountered during the process.

\section{Methodology}

The methodological framework for this investigation is an interpretive case study (Merriam, 1998). The reason for choosing an interpretive framework for this study is to provide a better understanding of the technology affordances and constraints of Web-based learning environments, and to generate analysis about the impact of technology tools, media and methods for fostering a cognitive apprenticeship model in a Web-based learning environment.

\section{Setting and content}

This setting for this investigation is a Web-based technology integration course entitled Integrating Technology and Education Practicum (I-TEP). I-TEP is a onecredit semester course for teacher education students of junior/senior standing. The focus of I-TEP is to model technology integration methods and strategies for preservice K-12 (primary through secondary) teachers. Currently I-TEP consists of five thematic modules. Each module focuses on both instructional design and the integration of a technology tool to enhance learning. Modules include learning theories (cognitive apprenticeship model), communication tools (email, electronic mailing lists, Web logs, instant messenger, and discussion groups), presentation tools (the Web, PowerPoint, graphic and audio software, and analogue and digital video), productivity tools (databases, spreadsheets, word processors, and graphical organizers) and the Web. In each thematic module, students are assigned readings and exemplars to view. Students are then required to respond to the readings and exemplars by using various communication tools (Web logs, email, instant messenger tools, etc.). Next, students complete assignments in which they design lesson plans integrating a specific type of technology tool to enhance learning. Concurrently, students also produce educational media using the tool integrated in the lesson plan. 


\section{Data collection}

The data presented in this study were collected during the summer 2005 semester. Observation data were gathered from 42 students (three graduate and 39 undergraduate students) from 11 different teacher education licensure programs. All of the students in this study gave consent for participating in the study, and all participants' names have been changed to preserve anonymity. Additionally, 21 students participated in email interviews.

\section{Findings}

\section{Modeling: tools, media and methods}

Cognitive apprenticeship methods were manifested and integrated in the Web-based environment in several ways. Modeling was supported through the use of text-based models and exemplars of lesson plans. Additionally, students were presented with models and exemplars of a variety of educational media created using various technology tools. Modeling was also provided for fostering both skill and cognitive development through a series of digital videos and Flash animations and text-based instructions called Over My Shoulder (OMS). The OMS media were not skill-based tutorials, but instead were designed to demonstrate internal processes the instructor went through to create educational media. The OMS videos consisted of video captures of the instructor's computer screen while she created educational media using a particular tool. The sound track consisted of the instructor using a 'thinkaloud' protocol to reveal the thought process in which the instructor engaged while creating educational media. The videos and animations were specifically not skill tutorials because they purposefully included errors made by the instructor along with articulated problem-solving strategies the instructor used to overcome problems and errors that occurred. For example, one assignment required students to create a WebQuest using their choice of Web-editing software. Students could select from a variety videos or animations in which the instructor used the corresponding Web editing software (Macromedia Dreamweaver, Microsoft Frontpage, Netscape Composer, etc.) to create a WebQuest.

The purpose of the OMS media was to allow learners look over the instructor's shoulder and to see and hear the internal processes the instructor when through while creating educational media. The $O M S$ Flash animations were similar, but instead of a sound track relied on thought balloons to articulate internal processes. The $O M S$ videos and animations purposely included some common mistakes and other problems encountered while creating educational media. The instructor modeled and explained how she dealt with problems and issues that occurred while working with technology. By watching, listening and even following along with the videos and animations, students observed the instructor modeling problem-solving and troubleshooting techniques while creating educational media with various technology tools. The purpose of the OMS media was to illustrate techniques and skills, but more importantly to model methods and techniques for problem-solving while using technology tools. 
The $O M S$ media was also designed to provide various levels of scaffolding. The $O M S$ videos provided the greatest amount of scaffolding through the use of both video and sound. The Flash animations offered less scaffolding. Learners could view the process, but instead of a soundtrack thought-balloons were used to articulate internal processes. The text-based instructions provided the least amount of scaffolding.

Enablers. All of the students enrolled in I-TEP had their own computers. The majority of students in this study had broadband Internet access either from their homes or from locations in or near the university. The university provides discount pricing for broadband Internet access for all students living on-campus and in the local town of the main campus. Additionally, the university provides greatly discounted prices for students purchasing Microsoft Office software as well discount pricing for some Macromedia and Adobe products.

The OMS materials were offered in many formats. They were created in three file formats (Audio Video Interleave, QuickTime, and Macromedia Flash file format) to accommodate various Web browser plug-ins. Students had the availability of downloading the compressed OMS materials from the course web site. Additionally, students could request a set of CDs, a DVD, or VHS tapes of all of the OMS videos and animations.

Barriers. Requests for CDs and DVDs of the OMS materials occurred throughout the course. During the first week of the course, only five students requested CDs and one student requested a DVD of the OMS materials. However, as the course progressed, more students began requesting copies due to the time it took to download the files. All of the videos on the course web site were compressed and none of the students reported problems with expanding files; however, many reported having to a wait one or two hours while material was downloaded. Although initially there were more requests for CDs than DVDs, by the end of the semester there was equal demand for copies in each format. There were, however, no requests for VHS tapes.

During the span of the course, there were no reports of the course web site being inaccessible; however, occasionally some of the resource and reference web sites were unavailable. While occasionally a student would note this, none of the students reported this as a barrier to access. Instead, those students used the other resources provided. Additionally, there were no reports of Internet or email access being problematic during the time of the course. There were, however, eight more urgent reports of issues with accessing and/or downloading the videos. Eight students complained about the amount of time it took to download the media. It is interesting to note, however, that six of these complaints were expressed through email the evening before assignments were due. When these students were questioned as to whether this issue was a problem of access to technology or of time management, two stated that time management was probably the cause. 
I procrastinate a lot sometimes. (Mindy)

I should have started sooner. (Carrie)

The other four students failed to respond.

Observations of student performances through teacher-student interactions revealed that although students used all of the materials, the videos and animations seemed to have the most impact in modeling techniques and skills. During email interactions, students often referenced a specific $O M S$ video or animation.

$\ldots$ in that section of the video when you added the picture. (Cara)

... like the problem you had when you uploaded the webquest (sic) [referencing the video for uploading a webpage]. (Scott)

I did it the same way you did, but I must have made a mistake [referencing the video for uploading a webpage]. (Liz)

The OMS material was also the topic most discussed in student web-log postings and online interactions. In students' final reflections, many students seemed to strongly associate the use of cognitive apprenticeship methods with aspects of modeling found on the $O M S$ videos and animations.

The Cognitive Apprenticeship was very helpful when it came to these assignments. It was easy for me to follow and guided me along. (Sara)

I like the idea of using cognitive apprenticeship methods. I know that I learn so much more from watching someone else model something before I attempt it. (Todd)

I could watch someone perform the tasks to get an idea, but in order for me to realy [sic] learn and remember, I need to work it on my own. (Beth)

There were no reported problems or barriers with file formats, nor did any students request assistance for downloading plug-ins. While most students worked on the course from home, at various times, several reported using computers on campus because of having a wider range of software available and faster computers.

\section{Scaffolding and coaching: tools, media and methods}

Scaffolding refers to the temporary support framework provided to learners to support them in the process of extending competencies (Bransford et al., 2000). Within the ITEP learning environment, scaffolding was provided in many ways. First, each of the four thematic modules was designed to build upon skills learned in previous modules. The level of instructional support was also designed to scaffold learners in an attempt to foster independence and risk-taking for students. Scaffolding was provided in the type of assistance provided to students by the instructor. During the first two modules, students' email requests for assistance were answered within a time span of 2-10 hours; however, as the course progressed, students were encouraged to seek other means for assistance. As each module progressed, the response time for email requests for assistance became longer. For the final module, students had a 1524 hour delay in response. The purpose of imposing this delay was because, as future 
teachers, many of the students will need to find resources for problem-solving and trouble-shooting technology problems. Extending response times encouraged students, particularly those students who tended to procrastinate on assignments, to search the Web to find immediate answers to questions.

Coaching is part of the teacher's role within a cognitive apprenticeship environment. The role of the teacher is to coach students in the process of adopting expert practices and strategies by offering feedback, guidance and prompting when needed. Within the I-TEP Web-based environment, coaching was provided using many different strategies. First, email and instant messenger were used to answer initial questions and help learners get acclimated to the learning environment. A Web-log also provided a means of guidance and feedback. Because the course required students to create educational media, each student had access to their own individual online Web folder. The instructor also had full access and privileges to each student's Web folder. Students saved their work in this folder. As students created media and encountered problems, the instructor was able to look at look at the work-in-progress and prompt students and offer guidance.

Enablers. There were no reports of students being unable to access their email. Students used email as the primary tool when requesting assistance, although a few students used Instant Messaging tools. Students received feedback via email and there were no reports of students not receiving feedback. There were five students who voiced complaints about timely responses to email on the due day of the first major assignment. However, the requests were sent two to three hours before the due date and time of an assignment. Students were informed that email was answered in the order in which it was received. When asked, all five admitted to procrastinating. It is interesting to note that four students appeared to change their work habits and submitted subsequent work well before the final due date and time.

All student work was uploaded into student web folders. In one of the initial assignments, students changed the permission settings on their web folder to allow the instructor access. When students encountered problems, they emailed the instructor who then could access the work and help coach the student in the problem-solving process.

Barriers. While email worked well for coaching, several students provided feedback at the end of the course recommending the use of a chat tool for synchronous coaching. They felt the process might have been more effective if they could get immediate access rather than using email; however, email was an important tool because it forced students to reflect and to at times seek alternative methods for problem-solving. Because answers were not provided on-demand, students often had to rely on other methods. In turn, this delay was part of the scaffolding process. Most $\mathrm{K}-12$ teachers do not have immediate access to on-demand technical problem-solving. It could be argued that the short delay many students experienced in an asynchronous environment helped foster new avenues for problem-solving. 


\section{Exploration, reflection, articulation: tools, methods and media}

Within a cognitive apprenticeship framework, learners should be encouraged to explore new ideas and viewpoints, and to form hypotheses and test them (Enkenberg, 2001). Exploration in the I-TEP learning environment was supported in several ways. Learners were presented with a wide variety of models and exemplars of lesson plans and corresponding educational media. They were encouraged to look at resources critically and to reflect and articulate their ideas and thoughts to their Web-logs. At the start of each module, learners were required to reflect upon their initial thoughts about the topic of the module and their opinions of the relevance of the tool-type for teaching and learning. After the module activities, learners followed up with a final reflection. The purposes of the pre and post reflections were twofold. Because the course content focuses on both instructional design of lesson plans and skill development, the reflections were used to foster students in becoming critical consumers of educational technology as well as to become aware of their learning processes while developing technology skills.

Enablers. Because I-TEP is a general education course, materials had to be either very general in nature so they would be relevant for students from a variety of teacher education programs or they needed to be curriculum-centered with enough samples relevant to each of the teacher education programs. In I-TEP, students were provided with both. Generic samples where used to introduce concepts, then students were provided with curriculum-specific examples to explore concepts related to their field. There were no reports of a lack of relevant exemplars, artifacts and resources to explore from students from any of the teacher education programs.

Several of the technologies such as group blogs and reflection questionnaires enabled students multiple means of reflection and articulation. Additionally, because all student work was accessible via the Web, students could view each others' work, which further enhanced articulation among students.

Barriers. There were no reports of students not being able to access group blogs, reflective questionnaires or other students' work; however, there were five reports of students being unable to access resource web sites. This did not appear to cause much difficulty because a variety of supplemental resources for each teacher education program had been provided.

\section{Summary}

Overall, the combination of tools, method and media outlined seemed to foster cognitive apprenticeship methods within a Web-based learning environment. However, it should be noted that this initiative represented a significant investment of time and energy for the instructor. Typically, faculty expect to invest time and energy in developing curriculum, materials and resources for teaching; however, a 
Web-based environment is much more time-intensive. The $O M S$ videos, although easily created with Camtasia screen-capturing software, took a great deal of time to create. Additionally, the Flash animations also represent a significant time investment. Although the materials, web site, blog, questionnaires and Web-based curriculum design were also time-consuming, the greatest investment of time was in teaching the course. Coaching and scaffolding along with supporting reflection and articulation can be significant in a traditional classroom; however, typically the raditional classroom is time-locked with a beginning and end to class time. In a Webbased environment, there is no time-lock beyond those that a teacher imposes. Without time-lock limits, coaching students can rapidly become an ongoing teaching experience, which, although it is a great enabler for students, can rapidly become a barrier for the teacher.

\section{Discussion}

One of the main concerns of educators teaching in a distance learning environment is the issue of access. Overall, there were few problems of access to most of the course materials. Although the various components of cognitive apprenticeship methods were integrated throughout the course in various ways, the $O M S$ materials were some of the most apparent elements of modeling. Because the video and animation were not step-by-step 'how to' instructions, but rather were designed to illustrate and demonstrate thinking process while creating educational media, the OMS materials were an integral part of the course. Provisions such as options for downloading, a variety of file formats, and the availability of CDs and DVDs seemed to be an effective method for supporting the technique.

It is important to note that the participants in this study are students at a mid-sized liberal arts state university; however, the students at this university are predominantly from families in the upper-middle economic range. Most students had broadband Internet access. The selection of media in this study was based the technology access provided by the university and based upon prior experience with this student demographic. It is acknowledged that the students in this study may not be representative of the broad spectrum of students in educational licensure programs. The choice to present the course as a Web-based environment and the selection of media such as video and animation used in this study to support cognitive apprenticeship methods may be a barrier for many students.

Observations and students' reflections revealed that students found the OMS materials instrumental in modeling and used them as point of departure when requesting assistance. These findings are somewhat consistent with findings of Schrader et al. (2003). Whereas Schrader et al. found that the use of video case studies of best practices helped initiate conversation and allowed for multiple perspectives, observations and interactions with students in the I-TEP Web-based environment revealed that the use of video and animation allowed students to experience different methods of problem-solving - and for many students it helped foster a sense of presence in a distributed learning environment. 
This is interesting to note because Collins et al. (1989) stress the importance of modeling and coaching as methods of implementing cognitive apprenticeship methods. Jonassen (1999) argues that there are two types of modeling: behavioral modeling of overt performance, and cognitive modeling of covert cognitive processes. Whereas behavioral modeling focuses on psychomotor skills, cognitive modeling involves an externalizing of internal processes. The use of video and animation provided students with both overt behavioral modeling of skills, but more importantly the covert cognitive modeling of internal processes of decision-making and problemsolving along with rationales for choices and options.

\section{Conclusion}

The span of the qualitative case study is by no means comprehensive, but rather is intended to examine both how methods and media can foster the integration of cognitive apprenticeship methods. However, it is not the purpose of this study to prescribe methods for integrating cognitive apprenticeship methods in Web-based learning environments, nor to designate how an online course should be structured. Rather, the findings of this study revealed that various media and processes could help foster the integration of cognitive apprenticeship methods for a Web-based teacher education course. However, it should be noted that the applicability of these findings is context dependent. The students in this study had access to computer and Internet access that supported the use of video and animations, email, instant messenger tools and other Web-based tools. The premise of this investigation is that the cognitive apprenticeship model holds relevance for both modeling and the effective use of technology for pre-service teacher education students as well as being a viable model for the design of a Web-based learning environment.

\section{Acknowledgement}

The preparation of the research was supported in part by the Research Center for Educational Technology Research Fellowship. The ideas expressed in this paper do not necessarily reflect the position of the grant agency.

\section{References}

Bransford, J., Brown, A. \& Cocking, R. (Eds) (2000) How people learn: brain, mind, experience, and school (Washington, DC, National Academy Press).

Brown, J. S. (1998) Internet technology in support of 'communities-of-practice': the case of Xerox, Accounting, Management and Information Technology, 8, 227-236.

Brown, J. S., Collins, A. \& Duguid, P. (1996) Situated cognition and the culture of learning, in: H. McLellan (Ed.) Situated learning perspectives (Englewood Cliffs, NJ, Educational Technology Publications, Inc.), 19-44.

Collins, A., Brown, J. S. \& Newman, S. E. (1989) Cognitive apprenticeship: teaching the craft of reading, writing, and mathematics, in: L. B. Resnick (Ed.) Knowing, learning, and instruction: essays in honor of Robert Glaser (Hillsdale, NJ, Lawrence Erlbaum Associates), 453-494. 
Collins, A., Brown, J. S. \& Holum, A. (1991) Cognitive apprenticeship: making thinking visible, American Educator, 15(3), 6-11.

Daviault, C. \& Coelho, M. (2003) Forum: a new approach to the production of educational content, paper presented at SIGGRAPH: International Conference on Computer Graphics and Interactive Techniques Educators program from the 30th Annual Conference on Computer Graphics and Interactive Techniques, San Diego, CA, 27-31 July.

Enkenberg, J. (2001) Instructional design and emerging models in higher education, Computers in Human Behavior, 17, 495-506.

Hannafin, M. J., Land, S. \& Oliver, K. (1999) Open learning environments: foundations, methods, and models, in: C. M. Reigeluth (Ed.) Instructional-design theories and models: a new paradigm of instructional theory (vol. 2) (Hillsdale, NJ, Lawrence Erlbaum Associates), 115-140.

Hendricks, C. C. (2001) Teaching causal reasoning through cognitive apprenticeship: what are results from situated learning?, The fournal of Educational Research, 94(5), 302-311.

Järvelä, S. (1995) The cognitive apprenticeship model in a technology rich learning environment: interpreting the learning interaction, Learning and Instruction, 5, 237-259.

Jonassen, D. H. (1999) Designing constructivist learning environments, in: C. M. Reigeluth (Ed.) Instructional design theories and models (vol. 2) (Mahwah, NJ, Erlbaum Associates), 215-239.

Liu, M. (1998) A study of engaging high-school students as multimedia designers in a cognitive apprenticeship-style learning environment, Computers in Human Behavior, 14(3), 387-415.

Liu, M. \& Y. Hsiao. (2002) Middle school students as multimedia designers: a project-based learning approach, fournal of Interactive Learning Research, 13(4), 311-337.

Liu, M. \& Pedersen, S. (1998) Hypermedia design and elementary school students, fournal of Interactive Learning Research, 9(2), 155-182.

Merriam, S. B. (1998) Qualitative research and case study applications in education (San Francisco, CA, Jossey-Bass).

Saarenkunnas, M., Järvelä, S., Häkkinen, P., Kuure, L., Taalas, P. \& Kunelius, E. (2000) NINTER - networked interaction: theory-based cases in teaching and learning, Learning Environments Research, 3, 35-50.

Schrader, P. G., Leu, D. J., Kinzer, C. K., Ataya, R., Teale, W. H., Labbo, L. D. \& Cammack, D. (2003) Using Internet delivered video cases, to support pre-service teachers' understanding of effective early literacy instruction: an exploratory study, Instructional Science: An International fournal of Learning and Cognition, 31, 317-340. 